\title{
Entertaining a False Reality: A social comparison examination of beauty pageant participation and the effect on body dissatisfaction, depression, and self-esteem
}

Angela Everhart

West Virginia University

Follow this and additional works at: https://researchrepository.wvu.edu/etd

\section{Recommended Citation}

Everhart, Angela, "Entertaining a False Reality: A social comparison examination of beauty pageant participation and the effect on body dissatisfaction, depression, and self-esteem" (2011). Graduate Theses, Dissertations, and Problem Reports. 3452.

https://researchrepository.wvu.edu/etd/3452

This Thesis is protected by copyright and/or related rights. It has been brought to you by the The Research Repository @ WVU with permission from the rights-holder(s). You are free to use this Thesis in any way that is permitted by the copyright and related rights legislation that applies to your use. For other uses you must obtain permission from the rights-holder(s) directly, unless additional rights are indicated by a Creative Commons license in the record and/ or on the work itself. This Thesis has been accepted for inclusion in WVU Graduate Theses, Dissertations, and Problem Reports collection by an authorized administrator of The Research Repository @ WVU. For more information, please contact researchrepository@mail.wvu.edu. 
Entertaining a False Reality:

A social comparison examination of beauty pageant participation and the effect on body dissatisfaction, depression, and self-esteem

\author{
Angela Everhart \\ Thesis submitted to the \\ School of Journalism \\ at West Virginia University \\ in partial fulfillment of the requirements \\ for the degree of \\ Master of Science \\ in \\ Journalism
}

Steve Urbanski, Ph.D., Chair

George Esper, Ph.D

Kelley Crowley, Ph.D

Elisa Krackow, Ph.D

Journalism

Morgantown, WV

2011

Keywords: Beauty Pageants; Self-Esteem; Depression; Media-Effects

Copyright 2011 Angela Everhart 


\begin{abstract}
Entertaining a False Reality:

A social comparison examination of beauty pageant participation and the effect on body dissatisfaction, depression, and self-esteem
\end{abstract}

by Angela Everhart

This study investigated the effects of beauty pageant participation on body dissatisfaction, depression, and self-esteem among women. A group of 20 women who participated in reality show beauty pageants as adults was compared with another group of 20 women who had never participated in beauty pageants. Pageant participants scored higher on body dissatisfaction as well as self-esteem. Neither group had mean depression scores in the clinically significant range. These findings suggest that beauty pageant participation among young adult women may influence their body dissatisfaction and self-esteem but may not have a significant effect on depression. 


\section{Table of Contents}

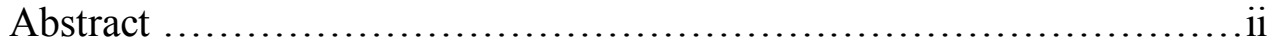

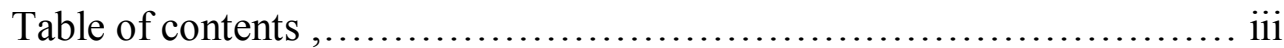

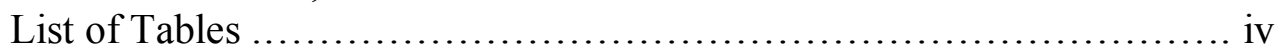

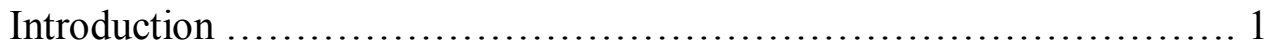

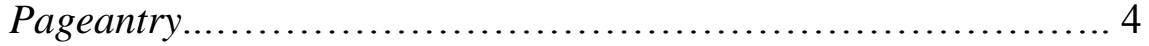

Related Media ................................................. 7

Guiding Theories ........................................... 10

Historical Relevance..................................... 12

Hypotheses .................................................... 22

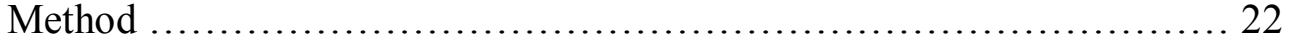

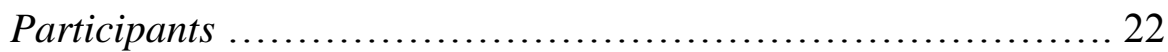

Apparatus ................................................. 24

Procedure ................................................... 25

Results ........................................................ 26

Discussion ........................................................... 31

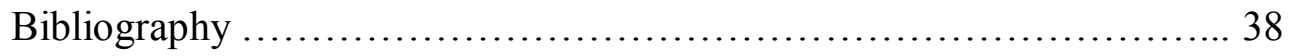




\section{List of Tables}

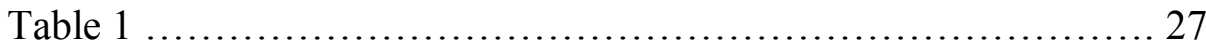

Table 2 .......................................................... 28

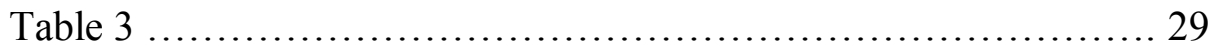

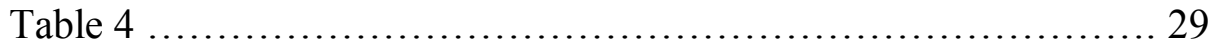

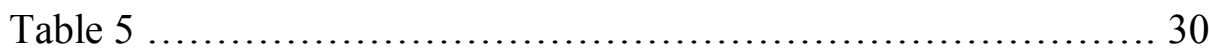

Table 6 ..................................................... 31 


\section{Introduction}

This study investigates beauty pageants and how they affect participant wellbeing. Beauty pageants were first introduced to Americans in 1854 by renowned circus owner B.T. Barnum, as an act to attract circus goers (howstuffworks.com). The event did not last long, though, as people did not support their sisters and friends being a part of a circus sideshow. Years later, The Miss America pageant, established in 1921 was historically understood to be an important civic ritual in the United States. It began as a bathing beauty attraction in Atlantic City and quickly gained popularity. Miss America grew to represent a wholesome, well-educated, hard-working youth, whose title was attainable by ordinary women who worked hard (Levey, 2002). The pageant has changed immensely in the past 89 years, almost reverting to its circus-like history. In 2004 after attracting a record-low 9.8 million viewers, ABC dropped the event (Godleski, 2005). They moved the venue to Las Vegas and the Country Music Network and began to hype the advertisements up with reality show teasers. Art McMaster, the CEO of the Miss America Organization, claimed, "It dragged too much... we decided to cut it down to get a faster-paced, hipper type of show" (Huss, 2005). By hipper, though, McMaster meant drawing on elements from the reality-show craze.

Then, in 2008, the network TLC took over production of the pageant and produced lead-up reality shows to gather interest in the contestants and build them as personalities viewers could grow attached to. Additionally, TLC introduced an American-Idol style voting system for the pageant, which allowed the pageante"s top 15 finalists to be chosen 
by viewers. Like the reality-show mentor, American Idol, the Miss America pageant has that goal of making the winner a celebrity and increasing ratings (Stransky, 2010).

Since the morph of Miss America to more of a reality format, other pageants have followed suit. One popular television show airing today on the Learning Channel is called Toddlers and Tiaras, an intriguing, quite shocking look at the bizarre behavior and acts that parents and children do to win beauty pageants (Lieberman, 2011). A typical show features young babies crying and screaming because they do not want to participate and girls that are 4 to 8 years old making demands of their parents and coaches, acting like small divas. Many parents put wigs, hair extensions, fake eyelashes, fake spray tans and teeth whitening strips on their young children. A mouthpiece-type retainer called a "flipper," is often used to make children with missing front teeth look less gap ridden and more perfect (TLC television broadcast, 2009).

The childhood beauty pageant subculture was once frowned upon, especially after the media attention showed details on the 1996 murder of child beauty queen, JonBenet Ramsey. Media flashed pictures of the scantily clad 5-year-old with a full head of hair and a full face of makeup, posing like a 21-year-old seductress (Rich, 1997). Although the controversy made people cringe, the childhood beauty pageant scene quickly recovered, and is a $\$ 5$ billion industry with over 5,000 pageants held each year (Giroux 2009). In addition to Toddlers and Tiaras, The Women "es Entertainment Television group owns a reality show entitled Little Miss Perfect. This show follows 10 different families on their conquests to obtain beauty queen crowns. 
According to the New York Times, cable-aired shows, Miss America, Miss USA, Toddlers and Tiaras, Instant beauty Pageant, the Swan, Little Miss Perfect, American Idol, America's Next Top Model, The Biggest Loser, Dancing with the Stars, Style Me, Survivor, The Bachelor, and MTVs long list of dating shows are so popular that they gross up to $\$ 96$ million per show. These reality shows greatly influenced entertainment media culture (Jorissen, Ferraro, \& Sandau, 2008). Americans have over 200 reality shows that have been previously broadcasted, are currently broadcasted, or will be shown in the near future (realitytv.com). Just five years ago, reality television was barely heard of while today, six of the top 20 shows on network television are reality shows (zap2it.com). If the hundreds of cable and satellite channels were considered, that number would likely be even higher.

Despite being relatively new and extremely popular, little research has been done in the area of reality television, and virtually no research, other than those listed above, has been done on beauty pageant reality competitors. Although there have been some studies that examine the effects of reality television on viewers, sparse literature exists about how these reality television stars are affected by the media they are participants in. This study aims to address this gap. Specifically, this study will analyze the effects of beauty pageants in terms of body dissatisfaction, and self-esteem among pageant participants of the Miss America system - since 2006 when the competition morphed into a reality show - and non-pageant participants. It will also address whether there is an indication of depression among participants and non-participants. Research in this realm 
will help to gain a better understanding of today"s entertainment industry and how popular media is affecting both viewers and participants. With a better understanding of how reality television stars are affected, society will be informed as to the possible risks and rewards from such entertainment.

\section{Pageantry}

In a study of 131 beauty pageant contestants (Thompson \& Hammond, 2003), 48.5 percent of them reported wanting to be thinner, 57 percent admitted to dieting to try to lose weight at the time, and 26 percent had been told or believed that they had an eating disorder. Thompson and Hammond also found that adult women who have competed in beauty pageants numerous times as children, were likely to have a high sense of body dissatisfaction and a high risk for eating disorders.

Similarly, Wonderlich and Henderson (2005) found that participation in beauty pageants as a child increased the chances of eating disorders, body dissatisfaction, difficulty trusting interpersonal relationships, impulsive behaviors, and increased feelings of ineffectiveness as an adult when compared to adults who did not participate in pageants when they were children. Levy (2002, as cited in Wonderlich \& Henderson, 2005) found that many mothers of young pageant participants enrolled their children in competition because they believed pageants were a positive, beneficial experience. They suggested that children gained better social skills, listening skills, confidence, independence, poise, and talent, thus suggesting a greater self-esteem as they aged. They also suggested that beauty pageant participants could differ whether they were exposed to 
beauty pageants because they wanted to have fun, or if their parents made them participate in hopes of teaching life skills, etiquette, and values. Specifically, parents who believed pageants were a way of teaching values and etiquette may put more pressure on their daughters to obtain the thin-ideals of pageantry than parents who allowed their children to participate for simple enjoyment. In addition, Levy (2002) noted that pageant mothers became more serious about winning as pageant participation increased. Thus, increased pageant participation may be associated with increased parental pressure, creating a stronger pressure towards the thin ideal.

Children who grow up under the scrutiny of competition and spotlights can experience psychological hardships (Kreig, 2004) and have a tremendous amount of premature stress (Canning \& Hoffman, 2009). Not only do children dress up like adults and practice for long hours, but they also have to endure criticism and failures. Nussbaum (2010) found that the pressure and constant awareness of their own physical appearance, can be taxing on a child"s development. Exposure to competition, sexuality, and constant disappointed all tend to effect maturing children in a negative fashion. Child psychologists report that competition at a very young age inhibits children from forming positive relationships with other children (Lieberman, 2010). Failure to have healthy playtime with peers leads to delayed social development and various issues with the social capacity (azete.com, 2009). As shown in the reality-show Toddlers and Tiaras, jealousy and envy confuse the children and can potentially cause problems with friends 
and family relationships (Ransford, 1997). Children in high-stress situations such as beauty pageants prematurely discover their abilities as well as their limitations.

William Pinsoff, a clinical psychologist and president of the Family Institute at Northwestern University has said that focusing on perfecting one"s looks at such a young age unleashes destructive self-internalization thoughts, which leads to eating disorders and complications with body image (Nussbaum, 2010). The American Psychological Association (APA) Task Force on The Sexualization of Girls warns that consequences will arise when children engage in behaviors that are associated with sexuality. The APA reports that there is a strong connection between young female children (age 4-13) who are exposed to early sexuality and eating disorders, low self-esteem, and depression.

Although a wealth of knowledge exists on the effects of childhood beauty pageant participation, no studies have been done on women who compete in beauty pageants as adults. Wonderlich and Henderson as well as Thompson and Hammond, who are noted above, have both researched pageant contestants as adults, but they competed when they were children. One competition that has adult contestants is the Miss America Pageant. Because the competition is aired on television, media effects on the viewers is not surprising. Wideman et al (1992) found that over time Miss America Pageant winners grew increasingly thinner as the national average for female weight increased. This caused body dissatisfaction among a group of average American women when the thin ideal was not obtained. Likewise, in a more recent study, Rubinstein and Caballero (2000) found that Body Mass Index (BMI) values of pageant contestants dramatically 
decreased over an 80 -year period to underweight scores. BMI values were generally within the normal range (20-25) among contestants in the 1920s but were below normal (less than 18.5) among recent studies. In more recent years, not only have women in the entertainment industry been growing increasing thinner, but their breast size has also been increasing (plasticsurgeonnews.com, 2010). According to the American Board of Plastic Surgery, average women have followed their lead. Lingerie manufacturer Frederickees of Hollywood reported that in 1996 the average size of bras they sold was 34B. Currently, the average is a 36C. Over the last decade the percentage of American women who undergo breast implants in America is up 40 percent as compared with statistics in 2000. According to FOX News, this trend is anticipated to continue to rise 8 percent yearly, despite having some links to rare forms of breast cancers. Not only is the thin-ideal still relevant in society, but now, unrealistic proportions are becoming a trend. Beauty pageants that are being aired on television are transforming into intensely scripted, out-of-touch reality shows that normalize surgery and encourage it as a means to become an ideal woman.

\section{Related Media}

A wealth of psychological and sociological literature addressing the phenomenon of media effects have shown that exposure to the thin-ideal in the media can have negative and damaging effects for women (Levine \& Murnen, 2002). Many researchers have examined advertisements on television and in magazines and their variable affects on body dissatisfaction, self-esteem, thin-ideal internalization, weight dissatisfaction, 
depression, and eating disorders (Groesz et al., 2002). The significant impact of beauty pageant participation on body dissatisfaction, interpersonal distrust, and ineffectiveness can be linked to previous research done with mass media exposure. Pageant participation and mass media effects are similar in that they both expose females to an unrealistic thinideal.

In related research, Stice (2002) examined the socio-cultural emphasis on thinness in popular media and internalization of the thin-ideal. He suggested that over the past century, the ideal of female attractiveness in western culture has shifted towards thinness. Pressure to achieve the standard caused a self-internalization of the thin-ideal. Therefore, women who were unable to achieve the thin-ideal had a negative effect and feelings of body dissatisfaction that contributed to eating disorders.

In another study, eating disorders and illegal drug use have been reported among professional fashion models (Santonastaso, Mondini, \& Favaro, 2002). Mason (1997) found that in the mid-1990s, fashion models ${ }^{e e}$ average height was 5 feet, 9.7 inches and 122 pounds, while the average American woman was 5 feet, 5.4 inches tall and weighed 133 pounds. The corresponding trend among beauty pageant participants is best understood as the trickle-down effect of the influence of high-fashion models.

Gerbner et al (1980) found that the BMI for Playboy Magazine centerfolds decreased over time, while the average American female weight increased, thus creating a gap between thin ideal and actual weights. Hawkins et al (2004) suggested that women who had been exposed to the thin-ideal media images reported increased body 
dissatisfaction in comparison to women who did not view thin-ideal images. Stice and Shaw (1994, as cited in Hawkins et al) also found that participants who viewed the thinideal images were less satisfied with their bodies than women who did not see the thinideal images. However, in another study, Stice and Shaw (1997, as cited in Wonderlich $\&$ Henderson, 2005) found that college women exposed to magazines that depicted the thin-ideal experienced body dissatisfaction, depression, guilt, shame, stress, and insecurity. Likewise, Tiggemann and Pickering (1996) note that greater amounts of media exposure were associated with eating disorders and body dissatisfaction among college women.

In other research, Frost and Mekelvei (2004) found that self-esteem and body dissatisfaction were positively correlated among female university students. When men and women were both studied, body dissatisfaction and self-esteem were positively correlated among both groups; however, the women's group showed a more positive correlation (Furnham, Badmin, \& Sneade, as cited in Mewlvei, 2004). Abel and Richards (1994) noted a significant positive relationship between body dissatisfaction and selfesteem among a group of adult women. They also found a stronger correlation between self-esteem and body dissatisfaction among upper-class women than lower-class women. In another study, Kostanski and Gullone (1994) suggested a strong positive correlation between body dissatisfaction and self-esteem among adolescents between the ages of 12 and 18. 
These studies are a sample of a large number that have supported a link between the thin-ideal and body dissatisfaction, negative self-esteem, and eating disorders. Although there is a wealth of knowledge about print media and television advertisements, there is a lack of knowledge about the new reality television phenomenon and virtually no research on beauty pageants competitions that have morphed into reality shows. This study aims to fill this gap.

\section{Guiding Theories}

A common link between body dissatisfaction and the internalization of the thinideal is Social Comparison Theory (Stormer \& Thompson, 1996). Social Comparison Theory suggests that we seek to compare ourselves to others we believe are similar to ourselves, in order to determine our own levels of abilities and successes (Festinger, 1954). There are two major types of Social Comparison Theory. In the first type of social comparison theory, people compare themselves to others they perceive to be socially better than themselves. This leads to negative mood and threatens selfevaluation (Givens \& Girard, 1989). In downwards Social Comparison Theory, people compare themselves to others they perceive to be less fortunate than themselves. This generally enhances mood and feelings of self-worth (Wills, 1991).

With regard to the thin-ideal, Stormer and Thompson (1996) found that women who compared their bodies to other women had higher levels of body dissatisfaction. In addition, participants engaged in social comparison to thin models, thus demonstrating upwards comparison. Adolescent girls and college-aged women had increased negative 
mood (Tiggemann \& McGill, 2004), increased body dissatisfaction, more eating disorders (Field, Carmago \& Taylor, 1999), and more diminished beliefs of their own personal attractiveness (Martin \& Gentry, 1997) than controls who did not engage in social comparison.

Self-Discrepancy Theory also may provide a significant link between research on social comparison and media effects. Higher levels of self-discrepancy have been linked to emotional distress, disappointment and dissatisfaction (Higgins, 1987; 1989). In terms of beauty pageant participation, the current study will use the social comparison upward model to examine whether greater social comparison (in the case of pageant participants) will prove higher levels of body dissatisfaction and lower levels of self-esteem (selfdiscrepancy).

According to research, beauty pageant participation and related media have caused negative affects on body dissatisfaction and self-esteem on those who observe the pageants and related media (Thompson \& Hammond, 2003). Other literature suggested that there are positive correlations between body satisfaction and self-esteem among children and adolescents (Kostanski \& Gullone, 2004). They noted, however, that if other variables were taken into consideration, the results may change. Variables such as competition should be taken into consideration. Gerrard (1996) found that competition significantly increased self-esteem amongst third-grade children. This research suggested that because beauty pageant participation engages participants in many activities such as talent, interview, and swimsuit training, then their self-esteem would be higher than their 
peers who did not compete in pageants. The research also suggested that body dissatisfaction and depression may have been displayed more frequently amongst pageant participants.

\section{Historical Relevance}

The ideal beauty has evolved over time. In western civilization, women of the Renaissance did not worry about a few extra pounds. Instead, the opposite was true. Upper-class women distinguished themselves by having bleached blonde hair, a large, robust weight, and high foreheads. To achieve the look, they sat for hours in the sun to bleach their hair. They would also use onion skin dye and even plucked their hairlines to achieve a higher forehead. Renaissance paintings commonly show large, plump, and pale women. Many of Michelangelo"s sculptures of beautiful women displayed round backs, wide hips, robust breasts, and thick ankles. During the Elizabethan era, women copied Queen Elizabeth"s pale skin and red hair. Women and men would use white powder and red wigs to achieve what they perceived as the ideal look. Women would also use rouge to color their cheeks, eyebrows, lips, and to hide their veins. They also used egg-white paste to hold the makeup in place. Then, in the 18th century, men and women started using gigantic wigs. Their wigs often extended three feet in the air and were seldom washed. Often times, they even attracted vermin.

The first shift towards thinness can be traced to the United States. The country was swept up in the European Romantic Movement with ballets and operas presenting heroes of unearthly passion and heroines of goddess-like beauty. While men were 
striving to improve their mental strength and vigor, women were trying to obtain an unnatural physical standard. The first American fashion magazine debuted in 1828 called the Godey's Lady's Book. The publication set standards for women in every aspect of their lives. Young, pretty women were depicted with slender forms, tiny waists, and rosebud lips. Then, in the Victorian era, women started wearing corsets to make their waistlines smaller and to achieve the new trending hourglass figure that was deemed desirable for the working class. The style was advocated by everyone, even though it constricted lungs and limited air supply, squeezed livers and bladders, and dislocated stomachs (Wade, 2007).

Early feminists were strongly opposed to the shift in thinness and warned of a dangerous psyche for the American woman. Early women "s rights activist Harriet Beecher Stowe said in 1850, "We in America have gotten so far out of the way of womanhood that has any vigor of outline, when we see a woman as a woman ought to be, she strikes us as a monster" (Seid, 1989, p. 61).

Even though it had started, thinness was nowhere near modern day expectations. In 1908, an article was even published in Harpers Bazaar entitled, "How to Get Plump." Shortly thereafter though, the Gibson girl look portrayed an increasing interest in women in athletics and the athletic woman type. America was on the cusp of the industrial revolution and emphasis had been put on machines and equipment making everything run smoothly. There was no room for excess and human bodies were no different. They were to be as beautiful and as sleek as a well-oiled machine. Women"es magazines then started to advocate thinner figures and excess flesh was considered untidy, cumbersome, 
and awkward. During this time, women were gaining more freedoms and liberties as well. They were going to colleges and entering professions otherwise only known to men.

After World War I, modern trends towards weight loss were even more intensified. Designer Paul Poiret introduced a slender style to the fashion industry. Slim women with long legs were classy and beautiful and graced advertisements for sought after clothing. His style evolved into the flapper girls who rejected rules. They danced, smoked cigarettes, and drank alcohol. The newly emaciated woman was to be athletic, intelligent, and equal to her husband. Women were urged to be their husband ${ }^{\text {ee }}$ s friend and companion, and passionate lover, and not just their wives. This was much different than their former matronly ancestors. In Fasting Girls, Joan Jacobs (1998) writes, “A women with a slender body, distinguished herself from the plump Victorian matron and her old-fashioned ideals of nurturance, service, and self-sacrifice. The body of the „new woman ${ }^{\text {ee }}$ was a sign of modernity that marked her for more than traditional motherhood and domesticity" (p. 245).

The so-called swinging 1920s, offered women many new freedoms, but the idea of athleticism and thin lanky-clad models in fashion advertisements, also offered critical judgments about weight and beauty. The first Miss America pageant was held during this time in which women were paraded around in their bathing suits and the winner"es physical measurements were considered ideal and something for normal women to obtain. Then, during the Great Depression, women were still encouraged to be thin and 
any excess weight was considered selfish. However, it was important to maintain a nice balance of weight, so as not to look too thin like one was starving.

In the 1940s, the buxom pin-up girl made its way into pop culture, and designers such as Christian Dior introduced new looks featuring shapely models (Brickell, 2009). Curves were considered to be shapely, and again the hourglass figure was considered the utmost sexy. It was important not only to be slim but also to have a large bust and curvy hips. Women may have been saved from the thin-ideal at this pivotal time, but as men returned from war, women who were independent, self-sufficient, and slim gained interest. The preference for a slim figure prevailed and women "s magazines began publishing almost 10 times as many weight loss articles (Meadow \& Weiss, 1992). The ideal weight had some fluctuation, but the most sought after looks were thin ones.

By the 1950s and 1960s full-figured women like Marilyn Monroe were considered the ideal feminine beauty (Levine \& Smolack, 1994). Although she was a size 12 in her movies (much larger than today ${ }^{\text {ee }}$ s ideal body type) she was idolized by many men and women. The 1960s presented an era of change. Political upheaval about the Vietnam War created a revolution in all aspects of people se lives. Sexuality was transformed by the availability of contraceptive pills, and love and nudity were common. The absence of clothing though, meant the absence of extra pounds. Poverty had become chic and there was no single look. The fashion industry struggled to reign in trends.

By the late 1960s and 1970s, however, sever prejudices towards overweight people began to take root in American culture. Fat was considered disgusting and women who were overweight were embarrassed and ashamed about their eating habits, as doctors 
pronounced them obese and overweight (Freedman, 1986). The svelte were considered to be quicker, more competent, better adjusted, and more moral than the fat people. Health was entirely redefined in the 1970s and 1980s. Cellulite was considered unacceptable no matter what one se weight, and everyone was encouraged to be an athlete, or at least look like one (Jacobs \& Brumberg, 1997).

These attitudes towards thinness have continued, and are increasingly growing thinner (Schwitzer, 2001). Today, just 50 years since the days of Marilyn Monroe, the average television actress is a size 2 , down 10 sizes from the size 12 ideal. The average actress, model, and dancer, are thinner than 95 percent of the entire female population (Levine \& Smolak, 1994). In effect, popular media has decreed that 95 percent of women to be unacceptable. Because of these thoughts, over one million young women do irreversible damage to their bodies and their psyches annually as a result of eating disorders (Wolf, 1991).

In The Beauty Myth, Wolfe (1991) writes about women"s curse of beauty, In the regressive 1950s, women "s natural fullness could be briefly enjoyed once more because their minds were occupied with domestic seclusion. But when women came en masse into male spheres, that pleasure had to be hidden by an urgent social expedient that would make women"s bodies the prisons their homes no longer were (p. 184).

Additionally she writes,

The great weight shift must be understood as one of the major historical developments of the century, a direct solution to the dangers posed by the women "s movement and economic and reproductive freedom. Dieting is the most potent 
political sedative in women "s history; a quietly mad population is a tractable one... concern with weight leads to a virtual collapse of self-esteem and sense of effectiveness, (p. 187).

Wolfe goes on to explain that the prolonged dieting in women changes their personalities. Women are more passive, anxious, and emotional when they are not eating enough. In a sense, she believes that by keeping women thin, society is keeping women suppressed.

The standard of beauty is constantly evolving cross-culturally and changing with the times. Although the opinion of beauty varies throughout time and through cultures, there is also proof of a universal idea of beauty. The Human Face, a documentary that debuted in 2001, did an experiment on universal beauty. Eighteen photographs of various women, aged 14 to 30 were shown to people all over the world. In the study, evaluators were asked to rank the photographs from most to least attractive. Surprisingly, 97 percent of the evaluators ranked the photographs exactly the same. Even the age and ethnicity of the evaluators did not matter.

People who are young with smooth skin and have well-proportioned bodies with average features have always traditionally been considered to be the most beautiful throughout history. Koinophilia (averageness) has been a strong indicator of beauty throughout time. Francis Galton (1883) first noticed this when he overlaid images of the faces of people who were vegetarian and those who were criminals to see if there was a typical appearance for both groups. He noticed while doing his study that the images together were more attractive than any of the images individually. Other researchers 
replicated Galton "es results and found the same. The mathematical average of a series of faces are rated more favorably than individual faces. It makes sense that through evolution people are sexually attracted to mates who possess predominately common features (Koeslag, 1990).

Another common study to analyze what makes women beautiful has been the waist-to-hip ratio experiment. The 0.70 waist-to-hip ratio is considered to be the best proportion for women. Physiologists have found that women who have hourglass figures are more fertile that other women and causes subconscious attraction from men. The early Greek philosophers saw a strong connection between beauty and mathematics. They founded the golden rule, which says that objects and people in proportion are the most aesthetically accepted. Even ancient Greek architecture is based on this idea of symmetry and proportion (Bulkens, 1999).

Stephen Marquardt (2002), a southern California plastic surgeon, developed the "beauty mask" to help him do a better job when performing plastic surgery. It is a computer program with a "mask" that fits over a person"s face, to figure out what needs to be done to them in order to achieve an attractive ratio. Marquardt says that our attraction to another person "s body increases if the body is symmetrical and proportional. Likewise, if a face is in proportion, we are more likely to perceive it as beautiful. Scientists believe that we perceive proportional bodies as more healthy.

In Leonardo Da Vincies "Vitruvian Man," the golden ratio is shown in body dimensions. Da Vincies drawings of the human body emphasized its proportion. The ratio of the following distances is the Golden Ratio: foot to navel and navel to head. The 
famous sepia sketch of a nude, spread-eagled person touching a square and a circle with his extremities, asserts the eerie proportional coincidences of the ideal human form (arm span = height; height $=$ hand length $\mathrm{x}$ 10) (Marquardt, 2002). However, it said nothing about the face. Marquardt collected photographs of faces the world deemed beautiful and began measuring their dimensions. He found that these beautiful people all had the same thing in common: the golden ratio. Their mouths were 1.618 times wider than their noses and their noses 1.618 times wider than the tip of their noses. As his data set expanded, Marquardt found that the perfect face was ridden with golden ratios. Even the triangle formed by the nose and the mouth was a perfect acute golden triangle. This golden ratio, or golden section, is based on Fibonacci numbers. Basically, every number in the sequence, after the second number, is the sum of the previous two numbers $(1,1,2,3,5$, $8,13,21$, etc.); in other words, the ratio between the whole and one of its parts is the same as the ratio between its two parts. The Fibonnaci numbers eventually lead to the Golden Ratio where phi $=1.618033$. The golden ratio face mask that Marquardt created shows that the length of the nose, position of the eyes, and length of the chin, all conform to some aspect of the Golden Ratio. When placed over the photo of any person, the proportions fit the face of people who are considered mathematically beautiful (Maddox, 2007).

Similarly, buildings are more attractive if the proportions used follow the Golden Ratio. Architects and artists throughout history used this ratio to produce objects of great beauty (such as Michelangelo"s "David," the Greek temples, and the Parthenon in Greece.) The Golden Ratio also occurs in nature, in the patterns we see in sunflowers, 
pine cones and so on (Gedney, 1985). This is largely because one of the best ways to efficiently pack things tightly together is using the Fibonacci sequence.

It is not surprising then that society also considers beautiful, thin, proportioned people to be more successful. According to a study done by Slater (2007), even infants prefer those who are more attractive over those who are less attractive. In his study, infants were shown pictures of 30 female faces of models and non-models. The results showed that infants spent 60-65 percent of their time looking at the more attractive faces. Dr. Slater determined that perception of good looks is innate, not a learned process.

Over the years, economists have recognized the impact of beauty in society. Even voters were found to favor more attractive candidates. Men were more likely to vote for attractive women candidates and women were more likely to vote for candidates they believed attractive and approachable (Hal, 2006). It has been suggested that physical beauty can be directly correlated with higher employment wages. Attractive men and women are paid more than average looking people are paid for doing the same degree of work (Varian, 2006). In a study done by Rosenblat and Mobius (2006), a group of potential employees were evaluated by a group of employers. The participants were evaluated on how well they solved various maze type puzzles. Then, both the employees and the employers predicted how many puzzles each candidate thought they could solve in the future in a given amount of time. They found that not only did the attractive candidates have more confidence in themselves and the amount of mazes they could solve, but the employers also had more confidence in them as well. In reality, the candidates considered to be beautiful were no more productive than the ordinary people 
were. Patrick Hicks, an attorney at the Las Vegas Office of National Employment said, "Everything else being equal, certain businesses -retail is the best example- would prefer people who are physically attractive." The basic thought is that an attractive person will represent a company better than a less attractive person (Shahani-Denning, 2010). Hammermesh and Biddle (1995) suggested that below-average looking people tend to earn 9 percent less per hour. On the other hand, above-average looking people tend to earn 5 percent more per hour than average people. Not only do pretty people make more money, but they also are more likely to be hired in the first place (Shahani-Denning 2010). Images of female bodies and body parts are all over the world, selling everything from food to cars. Women on advertisements make billions of dollars. As a result, the women who are insecure about their bodies because they do not compare to the models in the advertisements are spending their money on beauty products, new clothes, and dieting fads. The global fashion industry is estimated to be worth $\$ 900$ billion a year (BBC, 2003).

Beginning during the 1960s, a preference for thinness caught on in other Western nations as well. However, due to a unique social, economic, and political developments favoring the thin-ideal, no other cultures"e women suffer from as much anxiety about weight, dieting and exercise than American women (Fraser, 1997). Fifty percent of young female women in America are currently trying to lose weight, even though the majority are at or below normal weight (Rosen, Tacy, \& Howell, 1990). Even young children are affected by the thin-ideal. Research indicates that girls as young as 10 fear getting fat, restrict their eating and binge eat (Mellin, 2010). Perhaps Naomi Wolfe"s 
(1998) thoughts about the oppression of women will always hold true, "It"s the beauty myth, an obsession with physical perfection that traps the modern woman in an endless spiral of hope, self-consciousness, and self-hatred as she tries to fulfill society"s impossible definition of "the flawless beauty" (p. 185).

\section{Hypotheses}

Based on the literature reviewed, it is hypothesized that:

H1: Women who have participated in beauty pageants will have a greater sense of body dissatisfaction than women who have not competed in beauty pageants.

H2: Pageant participants will more likely have higher levels of depression when compared to women who did not compete in beauty pageants.

H3: Pageant participants will have a higher self-esteem than their non-participant peers.

\section{Method}

\section{Participants}

Participants in this study consisted of two groups of 20 women. The first group consisted of women who live in Hawaii and have participated in one or more beauty pageants in the Miss America pageantry system. They were between the ages of 17-24 during the time of pageant participation. The average age of the participant group was 21. Racially, there were 10 Pacific Islanders, three Caucasians, one African American, one Hispanic, and five biracial or other races. The second group of 20 consisted of three 
women from Hawaii and 17 women from West Virginia who had never participated in beauty pageants. They ranged in age from 15-62, with an average age of 32 . Racially, there were three Pacific Islander, 11 Caucasian, three African American, one Hispanic, and two biracial group members. Participants were chosen randomly based on their availability and willingness to participate. The researcher was in Hawaii when initially collecting data, and finished in West Virginia, explaining the variance in the makeup of the groups.

The two groups of 20 pageant participants and 20 non-participants were read a cover letter asking if they would like to participate and explained the details of the survey. Both surveys were hand distributed to all 40 participants who were willing to participate. All participants were told that the researcher was a West Virginia University graduate student who was conducting research for a thesis. Participants were assured of their anonymity and were asked to complete three surveys. After the surveys were completed, participants were asked to place the surveys into a large brown envelope for anonymity. After the surveys were filled out, the researcher collected all of the data and entered and analyzed it with the latest version of SPSS.

This researcher, a former beauty pageant contestant of the Miss America system, used five pageantry contacts to include in this study. These contacts included Miss America organization directors from Hawaii, Florida, and California and two former pageant winners from Hawaii. These five individuals were interviewed and asked to give their opinions. They were encouraged to elaborate on their answers and use their 
experience to answer the interview questions. This helped to add some qualitative data to a largely quantitative study. Wonderlich and Henderson (2005) have defined children pageant participants as being under 16 years old. Adult participants are over 16 years old. This study used the same range and considers any woman over the age of 18 to be an adult in this study.

\section{Apparatus}

All participants were asked to complete three questionnaires. The first questionnaire is the Hudson (1974) Index of Self-Esteem (ISE). The ISE questionnaire measures self-esteem and consists of 25 Likert-type questions, with 12 of those questions (number 3-7, 14-15, 18, 21-23 and 25) reversed for scoring. The answers range from $1=$ "rarely or none of the time" to 5= "most or all of the time." Scoring for the ISE ranged from 0 to 125 with scores over 30 indicating a low level of self-esteem.

The second questionnaire is adapted from Fallon and Rozin"es (1985) Questionnaire on Attitudes Toward Body Weight. It consists of six questions with the first four being informative and the last two measuring body image. Participants were asked about their age, ethnic makeup, current weight in pounds, and current height in inches (this information was used to calculate the participants $\left.{ }^{\text {ee }} \mathrm{BMI}\right)$. The last two questions asked participants to select two figures from a set of nine female body images. The images are graphically sketched figures numbered from 10 to 90 with increments of 10 in between figures. Figures grow larger as the numbers increase: 10 illustrates an underweight body 
image, 50 illustrates an average body weight image, and 90 illustrates an obese body weight image. The last two questions represent the participants ${ }^{\text {ee }}$ current appearance and what they would like to look like respectively. For this study, three scores were used from the final two questions. The first score indicated participants ${ }^{\text {ee }}$ current appearance, the second score indicated the figure that they would like to look like, and the third score indicated the discrepancy between the two scores, which determined their body dissatisfaction score.

The third questionnaire, the Center for Epidemiological Studies-Depression Scale (CES-D; Radloff, 1979) measures symptoms of depression they experienced in the past week. It consists of 20 Likert-type questions, with four of those questions (number $4,8,12$ and 16) reversed for scoring. The answers range from $0=$ "never" to $3=$ "most of the time." Scoring for the CES-D ranged from 0- 60 with scores over 16 indicating depression.

Lastly, a group of five pageant participants and directors were interviewed based off of a questionnaire that consisted of 10 questions. The first three questions were informative and the last seven questions asked about their involvement in pageantry and their perceptions about body dissatisfaction, self-esteem, and the thin-ideal in pageantry. They were given directions to elaborate on their answers.

\section{Procedure}

A research proposal was first submitted and approved by an Internal Review Board. Then, a cover letter was e-mailed to the group of five interviewees asking if they would 
like to participate and explained the details of the survey. The willing participants were later emailed a questionnaire and informed that their answers would not be anonymous and would be included in an academic thesis. They were interviewed using Skype, a software application that allows users to make voice and video calls over the Internet. The researcher asked 10 questions based off of the questionnaire that the participants were emailed. The answers were documented and key quotes and information were chosen to be included in the study.

\section{Results}

The Index of Self-Esteem (ISE) (Hudson, 1974) results supported hypothesis H3, that there would be a significant difference in self-esteem between women who had previously competed in beauty pageants and women who had never competed. Pageant participants were expected to have higher self-esteem than non-pageant participants. The mean self-esteem score for the pageant participant group was 12.9, while the mean score for the non-participants was 28.1. Higher scores correlated to lower self-esteem. Women who had competed in pageants had a lower mean score than non-pageant participants, indicating that they had a higher self-esteem. The theoretical range for the ISE was 0100 , while the actual range was from 0-33 for pageant participants and 0-58 for nonparticipants. An independent groups t-test was used to compare the ISE scores between the two groups of women (shown in Table 1). The t-test indicated a significant difference between the two groups $(\mathrm{t}(38)=3.503, \mathrm{p}<.001)$. There was a standard deviation of 10.41 for the women who competed and a standard deviation of 16.37 for the women who did 
not compete.

Table 1

Self-Esteem Scores for Women

\begin{tabular}{|l|l|l|l|l|l|}
\hline Score & $\mathrm{N}$ & $\mathrm{M}$ & $\mathrm{SD}$ & Theoretical Range & Actual Range \\
\hline $\begin{array}{l}\text { Pageant } \\
\text { Participant }\end{array}$ & 20 & 12.9 & 10.41 & $0-100$ & $0-33$ \\
\hline $\begin{array}{l}\text { Non-Pageant } \\
\text { Participant }\end{array}$ & 20 & 28.1 & 16.37 & $0-100$ & $0-58$ \\
\hline $\mathrm{t}(38)=3.503, \mathrm{p}<.001$ & & & \\
\hline
\end{tabular}

Results from the questionnaire on Attitudes towards Body Weight (Fallon \& Rozin, 1985) supported H1; Women who have participated in beauty pageants will have a greater sense of body dissatisfaction than women who have not competed in beauty pageants. Women who had participated in pageants had a mean ideal body image score of 18.5, whereas non-participants had a mean of 33.0. Lower scores indicated a thinner body size. On average, pageant participants viewed a much thinner physique as ideal, whereas non-pageant participants viewed a much heavier physique as ideal. The theoretical range for the ideal body score was 10-90. The actual range for pageant participants was 10-50 and the actual range for non-pageant participants was $10-60$. The results of the Ideal Body Scores are depicted in Table 2. The t-test indicated a significant difference between the two groups of women $(\mathrm{t}(38)=3.688, \mathrm{p}<.001)$. There was a standard deviation of 13.48 for women who participated in pageants and a standard deviation of 11.29 for women who did not participate in pageants. 


\section{Table 2}

\begin{tabular}{|l|l|l|l|l|l|}
\hline Ideal Body Scores for Women & & \\
\hline Score & $\mathrm{N}$ & $\mathrm{M}$ & $\mathrm{SD}$ & Theoretical Range & Actual Range \\
\hline $\begin{array}{l}\text { Pageant } \\
\text { Participant }\end{array}$ & 20 & 18.5 & 13.48 & $10-90$ & $10-50$ \\
\hline $\begin{array}{l}\text { Non-Pageant } \\
\text { Participant }\end{array}$ & 20 & 33.0 & 11.29 & $10-90$ & $10-60$ \\
\hline $\mathrm{t}(38)=3.688, \mathrm{p}<.001$ & & & \\
\hline
\end{tabular}

The results for the body dissatisfaction scores, which were also obtained from the Questionnaire on Attitudes to Body Weight (Fallon \& Rozin, 1985), also indicated that there is a significant difference between the two groups. The body dissatisfaction score indicates the difference between the women's ideal body image and current body image. The pageant participants had a mean of 17.5 while the non-participant group had a mean of 8.0. The group of pageant participants had a significantly higher score on body dissatisfaction. The theoretical range for the questionnaire was $0-80$. The actual range for the pageant contestants was 0-30 while the actual range for non-pageant participants was $0-20$. Table 3 displays a summary of the scores. A t-test indicated that there is significant difference between the two groups $(\mathrm{t}(38)=3.442, \mathrm{p}<.001)$. The standard deviation for the pageant group was 10.20 and the standard deviation for the nonparticipation group was 6.96 . 


\section{Table 3}

Body Dissatisfaction Scores for Women

\begin{tabular}{|l|l|l|l|l|l|}
\hline Score & $\mathrm{N}$ & $\mathrm{M}$ & $\mathrm{SD}$ & Theoretical Range & Actual Range \\
\hline $\begin{array}{l}\text { Pageant } \\
\text { Participant }\end{array}$ & 20 & 17.5 & 10.20 & $0-80$ & $0-30$ \\
\hline $\begin{array}{l}\text { Non-Pageant } \\
\text { Participant }\end{array}$ & 20 & 8.0 & 6.96 & $0-80$ & $0-20$ \\
\hline $\mathrm{t}(38)=3.442, \mathrm{p}<.001$ & & & & \\
\hline
\end{tabular}

A Pearson"s $r$ correlation was used to measure the relationship between body satisfaction and self-esteem. The correlation is significant $(\mathrm{r}(18)=.494, \mathrm{p}<.05)$. This suggests that there is a relationship between body dissatisfaction and self-esteem among women who have competed in beauty pageants (shown in Table 4).

\section{Table 4}

\begin{tabular}{|l|l|l|l|l|l|}
\hline Body Dissatisfaction and Self-Esteem (participants) \\
\hline Score & $\mathrm{N}$ & $\mathrm{M}$ & SD & Theoretical Range & Actual Range \\
\hline $\begin{array}{l}\text { Pageant } \\
\text { Participant }\end{array}$ & 20 & 17.5 & 10.20 & $0-80$ & $0-30$ \\
\hline $\begin{array}{l}\text { Non-Pageant } \\
\text { Participant }\end{array}$ & 20 & 12.9 & 10.41 & $0-100$ & $0-330$ \\
\hline $\mathrm{r}(18)=.494, \mathrm{p}<.05$ & & & & \\
\hline
\end{tabular}

A Pearson ${ }^{\text {ee }} \mathrm{r}$ correlation was used to measure the relationship between the body dissatisfaction score and self-esteem among non-participants. The resulting correlation proved to be significant $(\mathrm{r}(18)=.392, \mathrm{p}<.05)$. This signifies that there is a significant relationship between body dissatisfaction and self-esteem for women who have never competed in beauty pageants. 


\section{Table 5}

\begin{tabular}{|c|c|c|c|c|c|}
\hline \multicolumn{6}{|c|}{ Body Dissatisfaction and Self-Esteem (non-participants) } \\
\hline Score & $\mathrm{N}$ & M & SD & Theoretical Range & Actual Range \\
\hline \begin{tabular}{|l} 
Body \\
Dissatisfaction
\end{tabular} & 20 & 8.0 & 6.96 & $0-80$ & $0-20$ \\
\hline Self-Esteem & 20 & 28.1 & 16.37 & $0-100$ & $0-58$ \\
\hline
\end{tabular}

The Center for Epidemiological Studies Depression Scale (CES-D) results did not support the hypothesis (H2) that there would be a significant difference in depression between women who had previously competed in beauty pageants and those who had never competed in pageants. Pageant participants were expected to have higher levels of depression than non-participants. The mean depression score amongst the pageant participant group was 3.8 while the mean score for the non-participant group was 4.8 , with means from both groups in the nonclinical range. Because means for both groups were not in the clinical range, statistical analyses were not run. Higher scores correlated to higher depression. The theoretical range for the CES-D was 0-60, while the actual range was from 0-10 for the pageant participants and 1-12 for the non-participants. An independent t-test was done to compare the CES-D scores between the two groups (As shown in table 6). There was a standard deviation of 2.38 for the participant group and 3.25 for the non-participant group. 


\section{Table 6}

\begin{tabular}{|l|l|l|l|l|l|}
\hline Depression Scores for Women & \multicolumn{1}{l|}{} \\
\hline Score & $\mathrm{N}$ & $\mathrm{M}$ & $\mathrm{SD}$ & Theoretical Range & Actual Range \\
\hline $\begin{array}{l}\text { Pageant } \\
\text { Participant }\end{array}$ & 20 & 3.8 & 2.38 & $0-60$ & $0-10$ \\
\hline $\begin{array}{l}\text { Non-Pageant } \\
\text { Participant }\end{array}$ & 20 & 4.8 & 3.25 & $0-60$ & $1-12$ \\
\hline
\end{tabular}

\section{Discussion}

The results from both the Questionnaire on Attitudes to Body Weight (Fallon \& Rozin, 1985) and the Index of Self-Esteem (ISE) (Hudson, 1974) yielded significant data. It was hypothesized that women who had competed in beauty pageants would have greater body dissatisfaction and a higher self-esteem than women who had never competed in beauty pageants. In this study, beauty pageant contestants had higher body dissatisfaction scores, indicating a higher level of body dissatisfaction than women who never competed in pageants. These results are consistent with Wonderlich and Henderson es (2005) study that looked at body dissatisfaction and women who had participated in beauty pageants as children. In the current study, only three of the participants had competed in child beauty pageants as well. Wonderlich and Henderson found that women who participated in beauty pageants as children had higher levels of body dissatisfaction as adults than other adult women who had never competed in beauty pageants. This study differs, though, because it has focused on adult participants, not participants as children.

In this study, pageant contestants also reflected higher levels of self-esteem. These 
findings are consistent with Thomson and Hammond (2003) who found that children who have competed in beauty pageants numerous times are likely to have a higher selfesteem. Similarly, Levy (2002, as cited in Wonderlich \& Henderson, 2005) found that mothers who enrolled their daughters to compete in beauty pageants believed pageants taught their children better social skills, confidence and talent. In addition, Levy also found that some mothers of pageant contestants put more pressure on their daughters to obtain the thin-ideal, thus leading to increased body dissatisfaction for the contestants.

In addition to this research, a common theme is apparent in interviews conducted with beauty pageant directors and participants. Beauty pageants enhance self-esteem, but they also facilitate a sense of body dissatisfaction and concern about diet and exercise to obtain the thin-ideal. Ann Mata, a Miss America system pageant director for more than 25 years, explained that pageantry can lead young women to self-discovery, thus enhancing self-esteem. However, she also notes that the new reality show for the system is negative. She said,

I do not feel you need to see these young women doing the things they have them do. If it [the reality show] was used more a preparation for Miss America without having them jump into pools to win a challenge, or similar, then I would be more supportive (A. Mata, personal communication, June 4, 2010).

Keaolani Mento, a four-time pageant winner, explained, "For the average woman, it [pageant competition] is not beneficial to your body satisfaction; you always compare your body to other contestants" (personal communication, June 6, 2010). Another director, Bonnie Rontego suggested that because young women are vulnerable to 
influence, competition over looks could lead to eating disorders and a lowered sense of self-worth. She recalled,

I once trained a young woman who won the state title and became anorexic in an effort to win the national title. She did not feel that she was good enough or skinny enough to compete at the national level (personal communication, June 6, 2010).

This is a sad but true reality, insisted Sandra Mertins, Florida pageant director. She explained that pageantry could be a very positive and beneficial experience for a majority of young women; however, there are many that become obsessed with what they see on television and during competitions. She noted, "There has never been an overweight Miss America and there probably never will be. This leads girls who are average sized to strive for the thin-ideal” (Mertins, S. personal communication, June 6, 2010).

These opinions supported the hypothesis ( $\mathrm{H} 1$ and $\mathrm{H} 3)$ that beauty pageant participation increases self-esteem while also increasing body dissatisfaction. When asked about depression among participants, Mertins explained:

I think that all women struggle with a sense of insecurity at times and that is no different among pageant girls. As far as having serious medical conditions, I have only known of one girl in my 20 years of experience that had symptoms of depression and who was diagnosed. Other factors in her life at the time, I believe were key contributors to her condition. She tried to commit suicide but was not successful, thank God (Mertins, S. personal communication, June 6, 2010).

Mertins did not agree that pageant participation can cause depression among women, but she suggested that if other factors are considered, then it could happen. 
Since being in the pageant industry for 20 years, she only experienced one of her contestants showing signs of depression, so she thinks the chances for depression are low. In another interview with Leoni Furuya, she explored her experiences with depression as a contestant. She said she was never depressed during competition. However, if she did not win a pageant, she became extremely depressed for a period of time. She related it to a bad breakup:

When you lose a pageant, ites basically like the entire audience is telling you that the girl who won is better than you. By better, I mean, she"s more well-spoken, more confident, more talented, and worst of all, prettier. Losing a beauty pageant is like a bad breakup, where you're the one getting dumped. You sit at home and hide out and eat tubs of ice cream while watching old movies. Thankfully though, after a couple days, you feel better and can move on. So as far as depression goes, yes, pageants can cause short bouts of it, but not in the sense of clinically depression, at least not for as long of a period (Furuya, L. personal communication, June 10, 2010).

\section{Discussion}

Depression scores did not provide a significant difference between groups. Unlike Wonderlich and Henderson (2005), who found that beauty pageant participants had higher scores of depression and lower self-esteem scores, this study found the opposite to be possible. Beauty pageant participants had higher scores of self-esteem and lower scores of depression. Future research should look at this variable more. If there is a link to beauty pageant participation decreasing the likelihood of depression, then teen or young women who show signs of depression, may benefit from competing. Other 
variables should be looked at as well. For instance, competition in general and not necessarily only beauty pageants decrease depression scores. Results may vary between extra-curricular activities and competitive sports.

There are limitations in this study. There are less than 20 studies that have been done on beauty pageants. Can you be more specific here? "A few" is pretty vague. Remember, this is an academic study. It needs to be as precise as possible. They do not distinguish at what age participants competed, and most look at children participants. None specify how many times they competed, or what types of beauty pageants they competed in. The present study neglects to look at all of these variables as well. It does, however, look at what type of pageant - the Miss America Organization, after 2006 - and ages of participants from 17-24. Although this study did include ethnicity and age, there was not enough data collected to understand if there is a difference between age and race. Future studies should explore these variables more in depth.

In their study, Wonderlich and Henderson (2005) included only women who competed in beauty pageants as children to find that participation increased the chances of eating disorders, body dissatisfaction, difficulty trusting interpersonal relationships, impulsive behaviors, and increased feelings of ineffectiveness. The present study does not include those who competed as children, or how much pressure was put on the contestants at the time of competition, which could be another variable measured in the future. Levy (2002 as cited in Wonderlich \& Henderson, 2005) found that contestants who were pressured to achieve the thin-ideal, were more likely to have a higher level of body dissatisfaction than contestants who were not pressured. 
In addition, this study looked only at a group of Miss America participants who had competed in the Miss America pageant system. Different states and types of pageants may produce different results. This research did include two diverse locations, but there was not enough data to determine if location altered results. Also, the researcher is a former beauty pageant contestant; therefore, the groups studied and the interviewees selected may have reflected an unintended biased. If all of these variables were taken into consideration, future studies could compare all participants equally to achieve a more accurate idea about the effects of the Miss America beauty pageant participation on young women.

The results of this study and previous studies in this area indicated that beauty pageants can have a significant impact on women"s self-esteem and body dissatisfaction. Because fewer than 20 academic studies have been conducted in this area, it is important to continue future studies on beauty pageants and the impact that new forms of reality television will have on the concept of beauty pageants. of reality television. As reality television grows and reaches into many areas of media, future research in this area can prepare potential competitors on affects participation may have on them and their family members. This additional research will enable women of all ages and parents with daughters to know the potential risks and benefits of competing in beauty pageants and being aired on television for all to see. In a parallel realm, additional research also should be conducted in other areas of reality television and how the participants in those areas are affected. Ultimately, and most importantly, contestants will be capable of taking precautions before competing and being fully aware of risks involved in competing in 
beauty pageants and other forms of competitive reality shows before they make the decision to compete. Additional research can effect with whom the responsibility resides. Ultimately, directors, networks, and entertainment media in general may hold a larger sense of responsibility and liability in the future. Because of their money and ultimately power, people will continue to be greatly influenced by these body image ideals. 


\section{Bibliography}

Abell, S.C., \& Richards, M.H. (1996). The relationship between body shape satisfaction and self-esteem: An investigation of gender and class differences. Journal of Youth and Adolescents, 25, 691-703.

Banet-Weiser, S., \& Portwood-Stacer, L. (2006). I Just Want to Be Me Again. Feminist Theory, 255-271.

Bessenoff, G. R. (2006). Can the Media Affect Us? Social Comparison, SelfDiscrepancy, and the Thin Ideal. Psychology of Women Quarterly, 30, 239-251.

Brickell, C. (2009). Domesticating Prostitution: Study of an Interactional Gender. Space and Culture, 12, 232-249.

Bruno, M. (2007). Historical Evolution of the thin-ideal. Discover, 28(6), 20-22.

Bulckens, A.M. (1999).Logic numbers and the music of Greek architecture, Journal of Transfigural Mathematics, 4, 21- 47.

Fallon, A.E. \& Rozin, P. (1985). Questionnaire on attitudes to body weight. Journal of Abnormal Psychology, 94, 102-105.

Field, A.E., Carmago, C. A., Jr., Taylor, C. B., Berkey, C. S., \& Colditz, G. A. (1999). Relation of peer and media influences to the development of purging behaviors among preadolecent and adolescent girls. Archives of Pediatric Adolescent Medicine, 153, 1184-1189.

Fraser, L. (1997). Losing it: Americaes obsession with weight and the industry that feeds on it. New York: Dutton.

Frost, J. \& McKelvie, S. (2004). Self-esteem and body dissatisfaction in male and female elementary school, high school, and university students. Sex Roles, 51, 45-54.

Furnham, A., Badmin, N., \& Sneade, I. (2002). Body Image Dissatisfaction: Gender differences in eating attitudes, self-esteem, and reasons for exercise. The Journal of Psychology, 136, 581-596.

Furuya, L. Miss Kahala 2008. (2010). Interviewed by Angela Everhart. June 28. Online. 
Garner, D. M., Garfinckel, P.E., Schwartz, D., \& Thompson, M. (1980). Cultural expectations of thinness in women. Mass Media \& Society, 47, 483-491.

Gedney, L. (1985). Natureees Golden Ratio. Alaska Science Forum, 716.

Gerrard, L. E. (1996). Promoting Children"es Creativity: Effects of Competition, SelfEsteem, and Immunization. Creativity Research Journal, 9, 4, 339-346.

Gibbons, F.X., \& Gerard, M. (1989). Effects of upward and downward social comparison on mood states. Journal of Social and Clinical Psychology, 1, 14-31.

Groesz, L. M., Levine, M.P., \& Murnen, S.K. (2002). The effect of experimental presentation of thin media images on body satisfaction: A meta-analytic review. International Journal of Eating Disorders, 31, 1-16.

Hammermesh, D. (1995). Why it pays to look good. Working Woman, 20(3), 22.

Harpers Bazaar. (1908). How to get plump, 757.

Hawkins, N., Richards, S.P., Granley, M.H., \& Stein, D.M. (2004). The impact of exposure to the thin-ideal media image on women. Eating Disorders, 12, 35-50.

Hudson, W.W. (1974). Index of self esteem. Walmayr Publishing Company.

Huss, K. (2005). Miss America Seeks Relevance and Ratings: Pageant Telecast Slashes Talent, Takes a Page from Reality Programs. Retrieved January 1, 2010, from http://www.msnbc.com

Jorissen, A., Ferraro, R. F., \& Sandau, N. (2008). The Effect of Thinness Promoting Reality TV Shows on Being At-Risk for an Eating Disorder. Psi Chi Journal of Undergraduate Research, 13, 165-167.

Kostanski, M., Fisher, A., \& Gullone, E. (2004). Current conceptualization of body image dissatisfaction: have we got it wrong? Journal of child Psychiatry and Psychology, 45, 1317-1325.

Kostanski, M., \& Gullone, E. (1998). Adolescent body image dissatisfaction: Relationships with self-esteem, anxiety, and depression. Journal of Child Psychiatry and Allied Disciplines. 39, 255-263. 
Levey, H.L. (2002). Crowning Acheivements: Why mothers and daughters participate in child beauty pageants. Unpublished undergraduate thesis, Harvard University, Cambridge, MA.

Meadow, R. M., \& Weiss, L. (1992). Women's conflicts about eating an sexuality: The relationship between food and sex. Birmingham, NY: Harrington Park Press.

Marquardt, S. (2002). The Golden Decagon and human facial beauty. Journal of Clinical Orthodontics. 36 (6), 339-47.

Mata, A. Miss East Oahu Director. (2010). Interviewed by Angela Everhart. June 28. Online.

Mellin, M., Irwin, E., \& Scully, S. (1992). Prevalence of disordered eating in girls: A survey of middle-class children. Journal of the American Dietetic Association, 92(7), 851-853.

Mento, K. Miss Northshore 2009. (2010). Interviewed by Angela Everhart. June 30. Online.

Mertins, S. Miss Florida American Scarlet Pageant Director. (2010). Interviewed by Angela Everhart. July 1. Telephone.

Mobius, M. Markus, R., Rosenblat S., Tanya, S. (2006). Why Beauty Matters, American Economic Review. 15-22.

Reiss, S., \& Wiltz, J. (2004). Why People Watch Reality TV. Media Psychology. 6, 363378.

Rontego, B. Miss San Jose Preliminary Director. (2010). Interviewed by Angela Everhart. June 22, Online.

Rosen, J., Tacy, B., \& Howell, D. (1990). Life stress, psychological symptoms and weight reducing behavior in adolescent girls: A prospective analysis. International Journal of Eating Disorders, 9, 17-26.

Rubenstein, S., \& Caballero, B. (2000). Is Miss America an undernourished role model? Journal of the American Medical Association, 283, 1569-1576.

Seid, R. Never Too Thin: Why Women are At War With Their Bodies (1989). New York: Prentice Hall Press, 61. 
Shahani-Denning, C. (2010). The Effect of Physical Attractiveness on Selection Decisions in India and the United States. International Journal of Management, 27(1). 37-51

Silverstein, B., Perdue, L. \& Peterson, B., et al (1986). The role of the mass media in promoting a thin standard of bodily attractiveness for women. Sex Roles. 14, 519532.

Stice, E., \& Shaw, H.E. (1994). Adverse effects of the media portrayed thin-ideal on women and linkages to bulimic. Mass Media \& Society. 13(3), 288-308.

Stice, E. (2002). Risk and maintenance factors for eating pathology: A meta- analytical review. Mass Media \& Society, 128, 825-848.

Stormer, S.M., \& Thompson, J.K. (1996). Explanations of body image disturbance: A test of maturational status, negative verbal commentary, social comparison, and sociocultural hypotheses. International Journal of Eating Disorders. 19, 193-202.

Stranksy, T (2010). Who Killed Miss America? Entertainment Weekly, 1087, 60-61.

The Telegraph, (2010). Retrieved from http://www.telegraph.co.uk/science/sciencenews/7080729/Voters-prefer-attractive-politicians.html on May 28, 2010.

Thompson, S., \& Hammond, K. (2003). Beauty is as beauty does: Body image and selfesteem of pageant contestants. Eating and Weight Disorders, 8, 231-237.

Tiggemann, M., \& McGill, B. (2004). The role of social comparison in the effect of magazine advertisements on women se mood and body dissatisfaction. Journal of Social and Clinical Psychology, 23, 23-44.

Tiggemann, M., \& Pickering, A. (1996). Role of television in adolescent women's body dissatisfaction and drive for thinness. International Journal of Eating Disorders, 20, 199-203.

Turner, L. (2005). Television on the Cutting Edge: Cosmetic Surgery Goes Prime-Time. American Medical Association. Retrieved January 10, 2010 from http://www.ama.org

Hal, V., (2006). Beauty and the Fattened Wallet, the Economic Scene. Retrieved May 31, 2011 from www.newyorktimes.com. 
Wills, T.A., Similarity and self-esteem in downward comparison. Social Comparison: Contemporary theory and research. Hillsdale, NJ: Erlbaum. 1991, 51-78.

Wiseman, C.V., Gray, J.J., Mosimann, J.E., \& Ahrens, A.H. (1992). Cultural expectations of thinness in Women: An update. International Journal of Eating Disorders. 20, 199-203.

Wolfe, N., The Beauty Myth. New York: Bantham Doubleday Dell Publishing, 1991, 281

Wonderlich, A.L., \& Henderson, J.B. (2005). Childhood beauty pageant contestants: Associations with adult disordered eating and mental health. Eating Disorders. 13, 291-301.

Wyatt, E. Despite Lower Ratings, Cash Flow Rises for Idol. Retrieved from www.nytimes.com on March 10, 2010 